\title{
Occurrence and Antimicrobial Susceptibility Profile of Salmonella Isolates from Animal Origin Food Items in Selected Areas of Arsi Zone, Southeastern Ethiopia, 2018/19
}

\author{
Minda Asfaw Geresu ${ }^{D},{ }^{1}$ Behailu Assefa Wayuo $\mathbb{D}^{\mathbb{D}},{ }^{1}$ and Gezahegne Mamo Kassa $\mathbb{D}^{2}$ \\ ${ }^{1}$ Department of Veterinary Science, College of Agriculture and Environmental Science, Arsi University, Asella, Ethiopia \\ ${ }^{2}$ College of Veterinary Medicine and Agriculture, Addis Ababa University, Bishoftu, Ethiopia \\ Correspondence should be addressed to Minda Asfaw Geresu; minda.asfaw@gmail.com
}

Received 8 December 2020; Revised 22 February 2021; Accepted 22 March 2021; Published 31 March 2021

Academic Editor: Giuseppe Comi

Copyright (c) 2021 Minda Asfaw Geresu et al. This is an open access article distributed under the Creative Commons Attribution License, which permits unrestricted use, distribution, and reproduction in any medium, provided the original work is properly cited.

\begin{abstract}
The status of Salmonella and its antimicrobial susceptibility profile in animal origin food items from different catering establishments in Ethiopia is scarce. Hence, this study aimed to investigate the occurrence and antimicrobial susceptibility profile of Salmonella isolates from animal origin food items in the selected areas of Arsi Zone. One hundred ninety-two animal origin food samples were collected and processed for Salmonella isolation. Isolates were tested for their susceptibility to 13 antimicrobials using Kirby-Bauer disk diffusion assay. An overall prevalence of 9.4\% (18/192) Salmonella spp. isolates were recovered from animal origin food samples collected from different catering establishments. Seven (21.9\%) of "Dulet," 4 (12.5\%) of "Kitfo," 3 (9.4\%) of "Kurt," 2 (6.3\%) of raw milk, 1 (3.1\%) of egg sandwich and 1 (3.1\%) of cream cake samples were positive for Salmonella. Catering establishments, protective clothing, source of contamination, manner of hand washing, and money handling were among the putative risk factors that were significantly associated $(p<0.05)$ with Salmonella spp. occurrence. Ampicillin, nitrofurans, and sulphonamide resistance were significantly associated $(p<0.05)$ with Salmonella spp. occurrence in the selected food items. Three (16.7\%), 5 (27.8\%), 5 (27.8\%), and 4 (22.2\%) of the isolates were resistant to 3, 4, 5, and 6 antibiotics, respectively, whereas only a sole isolate was resistant to two antibiotics (viz. ampicillin and kanamycin). In conclusion, the general sanitary condition of the catering establishments, utensils used, and personnel hygienic practices were not to the recommended standards in the current study. Besides, detection of multidrug-resistant strains of Salmonella in animal origin food items from different catering establishments suggests the need for detailed epidemiological and molecular characterization of the pathogen so as to establish the sources of acquisition of resistant Salmonella strains. Hence, implementation of Salmonella prevention and control strategies from farm production to consumption of animal origin food items are crucial.
\end{abstract}

\section{Introduction}

Food-borne diseases occur as a result of consumption of contaminated food stuffs especially from animal products and are a major public health problem globally $[1,2]$. With constant changes in the global food trade dynamics, food consumption behaviors, food production environment and processes, and emergence and re-emergence of food-borne pathogens and chemical contaminants entering the food chain, food-borne diseases continue to be a growing problem. An estimated 600 million people, almost 1 in 10 people in the world, fall ill annually for consuming contaminated food and two million deaths are reported each year [3-5]. In developed countries, an estimated one-third of the population is affected by food-borne diseases each year [6]. However, the severity is higher among developing countries including Ethiopia due to poor food handling and sanitation practices, inadequate food safety laws, weak regulatory systems, lack of financial resources, and awareness about proper food handling which creates a conducive environment for the spread of food-borne and food poisoning etiologic agents $[7,8]$. 
Biological contaminants, largely bacteria, constitute the major cause of food-borne diseases [9, 10]. Among the bacteria, Salmonella spp. are considered the most prevalent food-borne pathogen that has gained increased attention worldwide in recent years [11] and has long been recognized as an important food-borne disease of economic significance in animals and humans [12], in both developing and developed countries, although incidence rates vary according to the country [13]. Salmonella is among common foodborne pathogens predominantly found in beef, poultry meat, pork, eggs, and raw dairy products, acquired directly or indirectly from human or animal excreta $[8,14,15]$. In many countries, high incidence of salmonellosis in man appears to be caused by infection derived from contaminated animal products mentioned above. The contaminated products cause disease as a result of inadequate cooking or crosscontamination of working surfaces in kitchen environment $[16,17]$.

In Ethiopia, a country in a developing sub-region that experiences the second highest food-borne disease burden in the world [18], the incidence of food-borne Salmonella infections has increased dramatically during the past few years. This might be due to unhygienic slaughter practices in the abattoirs, and widespread consumption of raw meat (Kitfo, Kurt, and Dulet) and traditional practices are potential factors contributing to the risk of exposure of the Ethiopian community to food-borne pathogens [1]. Studies conducted in different parts of the country have demonstrated the presence of Salmonella in different food animals and food products $[13,14,18-21]$. Despite these attempts to report the prevalence and distribution of Salmonella spp. in some animal origin food items, humans, and food animals in Ethiopia, the problem of this pathogen in foods of animal origin is still not well known. However, studies made elsewhere indicated that foods of animal origin are important sources of Salmonella, particularly among those raw food consumers.

The emergence of antimicrobial-resistant (AMR) in Salmonella is linked with horizontal gene transfer and these genes are found on mobile genetic elements. The expansions of antibiotic-resistant Salmonella serovars are efficient in worldwide dissemination [22, 23]. In recent years, AR Salmonella has become very common in clinical isolates of animal origin food items $[8,11,19,24]$. An increase in the resistance of Salmonella to commonly used antimicrobials has also been noted in both public health and veterinary sectors in Ethiopia [11, 13, 14, 19-21, 24, 25]. Salmonella strains resistant to various antimicrobial agents, particularly resistant to fluoroquinolones and third-generation cephalosporins, are considered as an emerging problem worldwide [26], resulting in higher morbidity and mortality rates and higher overall treatment costs. This may represent a public health risk by transfer of resistant Salmonella strains to humans through the consumption of contaminated food and food products.

Ease of access to and high frequency of antibiotic use, use of antibiotics at subtherapeutic levels, over-prescription at health facilities, close contact between animals, high antibiotic use in animals in small production systems, and contamination during handling animal products were among the several factors contributing to high antibiotic resistance in Ethiopia [27]. A recent study revealed very high multidrug resistance to more than two antimicrobial agents in isolates of Salmonella from food animals and in contact humans in Ethiopia and elsewhere including resistance to fluoroquinolones and third-generation cephalosporins [28-30].

Therefore, the absence of recent study on the isolation, identification, and antimicrobial resistance profile of Salmonella from food of animal origin purchased from different catering establishment in Arsi zone multifaceted with increased consumption of raw/minced meat (locally known as "Kitfo," "Dulet," and "Kurt"), raw milk, egg sandwich and cream cake by the community at large entails isolation, identification, and antimicrobial profile characterization of Salmonella food-borne infections that could complement the paucity of information in the selected study setting.

\section{Materials and Methods}

2.1. Study Areas. The study was conducted in Dera, Iteya, Asella, Bekoji, and Gobessa towns in different catering establishments from October 2018 to May 2019 in Arsi Zone of Oromia regional state, southeastern Ethiopia (Figure 1). Dera is the administrative center of Dodota district and has a latitude and longitude of $08^{\circ} 20^{\prime} \mathrm{N}$ $39^{\circ} 19^{\prime} \mathrm{E}$. The altitude of this town ranges from 1400 to 2500 meters above sea level [31], whereas Iteya, the administrative center of Hetossa district, is a town which is located east of Lake Zway with a latitude and longitude of $08^{\circ} 08^{\prime} \mathrm{N} 39^{\circ} 14^{\prime}$ and an elevation of 2215 masl [32]. Asella is located at a distance of $175 \mathrm{~km}$ southeast of Addis Ababa at $7^{\circ} 57^{\prime} \mathrm{N}$ and $39^{\circ} 7^{\prime} \mathrm{E}$ with an altitude of 1650 to 4130 masl. The annual rainfall of the study area ranges from 200 to $400 \mathrm{~mm}$ with mean annual temperature of $22.5^{\circ} \mathrm{C}$. The town is with about 367,269 human population inhabitants [33].

Bekoji is a town located at about $235 \mathrm{~km}$ southeast of the capital Addis Ababa on the highway towards Bale zone and known as the home town of many famous Ethiopian athletes. The town is the administrative center of Lemu-Bilbilo district located at the latitude and longitude of $7^{\circ} 35^{\prime} \mathrm{N}$ $39^{\circ} 10^{\prime} \mathrm{E}$ with an elevation of $2810 \mathrm{~m}$. The area receives an annual rainfall of around $1100 \mathrm{~mm}$ with the average annual temperature ranges from 6 to $26^{\circ} \mathrm{C}$. The human population of the town is estimated at 214, 000 inhabitants [34]. On the same way, Gobessa town is located $265 \mathrm{~km}$ southeast of Addis Ababa. Its altitude is between 1500 and $3400 \mathrm{~m}$ with an average altitude of 2450 masl. The average temperature is $18^{\circ} \mathrm{C}$ which varies between $10^{\circ} \mathrm{C}$ and $25^{\circ} \mathrm{C}$, with an annual average rainfall of around $1000 \mathrm{~mm}$. The town is the administrative center of Shirka district with estimated 183,823 human population inhabitants. In the above towns, a number of people are involved in the public service business, including smallholder farming supplying food animals and animal products to the communities and the slaughterhouse [35]. 


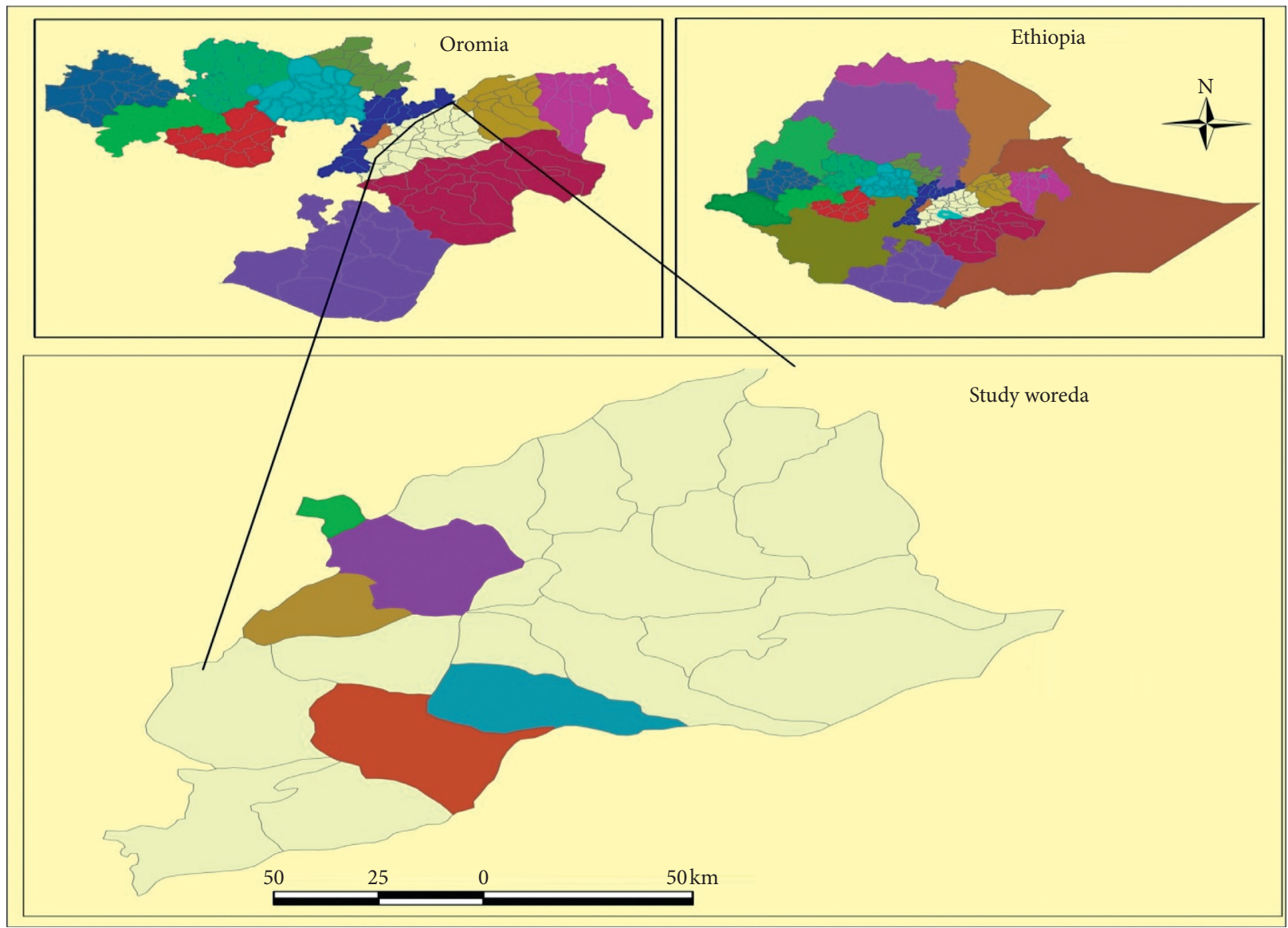

Study area
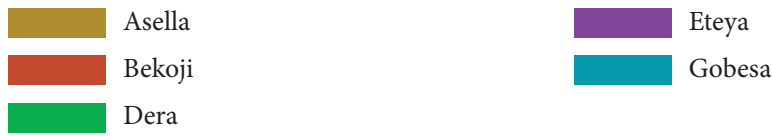

Figure 1: A map that shows study areas.

2.2. Study Design. A cross-sectional study was conducted from October 2018 to May 2019 to isolate, identify, and characterize antimicrobial susceptibility profiles Salmonella spp. from selected animal origin food items in selected towns of Arsi Zone and its suburbs.

Stratified random sampling from catering establishments and a list of frame of public places were used as sample source according to the accessibility of animal origin food items. First, functional catering establishments registered in the towns were searched for and then public places were stratified into strata (hotels, restaurants, cafeterias, and retail shops) and they were used as a sampling frame. Study foods of animal origin were selected during dining time using a simple random sampling method in each public place on proportional bases/considering the availability of the food items.

2.3. Sample Size and Study Methodology. Selected animal origin food samples were purchased from hotels, restaurants and cafeterias including minced meat (locally known as "Kitfo", "Kurt," and "Dulet"), egg sandwich and cream cake whereas raw milk was bought from retail shops/cafeteria. Time of sampling was scheduled at the beginning of the serving period (breakfast or lunch time).

The sample size calculation was based on $50 \%$ prevalence assumption (since there was no study on E. coli O157: H7 and Salmonella spp. from different animal origin food items in the selected towns of Arsi Zone), 95\% CI and df $=0.05$ [36]. Though the sample size calculated for Salmonella spp. was 384, only 192 samples were processed for bacteriological detection of Salmonella because of the limited number of catering establishments in the study settings as per our stratification. Hence, the total sample size was divided for the four (4) food of animal origin that was sampled (viz. 48 samples for each animal origin food was considered to maintain proportionality).

2.3.1. Method of Sample Collection. The selected animal origin food items including minced meat, egg sandwich, and cream cake samples purchased from the catering establishments were put in sterile plastic bags by using sterile forceps and spoons from the eating plate whereas 
approximately $10 \mathrm{ml}$ of raw milk bought from different cafeteria/retail shops was collected by using sterile screw capped bottle. All the collected samples were properly identified by sample type, date of collection and sources, and immediately transported to the laboratory (Asella Regional Laboratory, Veterinary Microbiology Section) in an ice box with freeze packs under completely sterile conditions for microbiological analysis.

2.3.2. Isolation and Identification of Salmonella Species. Standard cultivation method recommended by the International Organization for Standardization (ISO-6579) [37] with Global Salmonella Survey (GSS) and WHO guidelines [38] was carried out for isolation and identification of Salmonella. Briefly, $25 \mathrm{gm}$ of each food sample was weighed and homogenized in sterile stomacher bag (Stomacher 400R, Seward, England) with $225 \mathrm{~mL}$ of pre-enrichment buffered peptone water for 2 minutes. The nonselective preenriched sample, from each solid or liquid food sample, was mixed thoroughly and incubated overnight at $37^{\circ} \mathrm{C}$. Following incubation, $1 \mathrm{~mL}$ of the pre-enrichment broth was transferred to every $10 \mathrm{~mL}$ of tetrathionate broth (Muller Kaufmann, Oxoid, England), for the first selective enrichment of Salmonella growth while inhibiting other microorganisms, and incubated at $37^{\circ} \mathrm{C}$ for 24 hours. In addition, $0.1 \mathrm{~mL}$ of pre-enrichment broth was added to $10 \mathrm{~mL}$ of Rappaport-Vassiliadis (Oxoid, England) broth for second selective enrichment and incubated at $41^{\circ} \mathrm{C}$ for 24 hours.

For isolation of Salmonella species, each suspected colony from selectively enriched medium was streaked onto selective xylose lysine deoxycholate (XLD) agar plates and incubated at $37^{\circ} \mathrm{C}$ for $18-24$ hours. Salmonella suspected colonies, red color with a black center, from XLD agar medium were plated onto nutrient agar (Oxoid, England) for further biochemical confirmation. Biochemical tests: Salmonella isolates were identified using triple sugar iron agar (TSI), lysine iron agar, urea broth, indole test, and citrate utilization tests. These were incubated for 24 hours to 48 hours at $37^{\circ} \mathrm{C}$. Colonies producing an alkaline slant with acid bottom and hydrogen sulfide production on TSI, positive for lysine, negative for urea hydrolysis, negative for indole test, and positive for citrate utilization were considered as Salmonella. Finally, susceptibility to antimicrobial was performed for all isolates.

\subsubsection{Antimicrobial Susceptibility Testing for Salmonella} Species Isolates. Phenotypic antimicrobial susceptibility testing on Mueller-Hinton agar (Oxoid) using the agar disc diffusion method [39] was conducted to determine the antibiotic-resistant profiles of each isolate. Briefly, four wellisolated colonies from nutrient agar plates will be transferred into tubes containing $5 \mathrm{ml}$ of Tryptone soya broth (Oxoid, England). The broth culture was incubated at $37^{\circ} \mathrm{C}$ for 4 hours until it achieved the $0.5 \mathrm{McF}$ arland turbidity standards. Sterile cotton swabs were dipped into the suspension, rotated several times, pressing firmly on the inside wall of the tube above the fluid level to remove excess inoculums, and swabbed uniformly over the surface of Muller Hinton agar plate (Oxoid, England). The plates were held at room temperature for 30 minutes to allow drying.

Subsequently, the selected antibiotics were placed 15-20 $\mathrm{mm}$ apart from each other using sterile forceps to prevent overlapping of the inhibition zones and then, incubated at $37^{\circ} \mathrm{C}$ for 18 hours. A total of 13 selected antibiotic discs (Oxoid, UK) were included: ampicillin $(10 \mu \mathrm{g})$, amoxicillin-clavulanic acid $(30 \mu \mathrm{g})$, gentamicin $(10 \mu \mathrm{g})$, kanamycin $(30 \mu \mathrm{g})$, ciprofloxacin $(5 \mu \mathrm{g})$, chloramphenicol $(30 \mu \mathrm{g})$, trimethoprim-sulfamethoxazole $(5 \mu \mathrm{g})$, sulphonamides $(300 \mu \mathrm{g})$, tetracycline $(30 \mu \mathrm{g})$, nalidixic acid $(30 \mu \mathrm{g})$, ceftriaxone $(30 \mu \mathrm{g})$, streptomycin $(10 \mu \mathrm{g})$, and nitrofurans $(50 \mu \mathrm{g})$ (Table 1 ). Then, the plates were incubated at $37^{\circ} \mathrm{C}$ for 24 hours and finally the zone of inhibition was measured and interpreted as susceptible, intermediate, or resistant categories assigned on the basis of the critical points recommended by Clinical Laboratory and Standard Institute [39].

2.4. Data Management and Analysis. Data generated from laboratory investigations were recorded and coded using Microsoft Excel spreadsheet (Microsoft Corporation) and was analyzed using STATA version 14.0 for Windows (Stata Corp. College Station, TX, USA).

The prevalence of Salmonella spp. isolated from the selected animal origin food items was calculated as the number of positive (confirmed) samples divided by the total number of samples investigated (processed) in the laboratory. Logistic regression and/or descriptive statistics such as frequency, percentage, and/or proportion were applied to compute the collected data from the selected foods of animal origin and antimicrobial susceptibility test results.

\section{Results}

3.1. Overall Prevalence of Salmonella spp. Isolated from Animal Origin Food Items in the Study Settings. In the current study, an overall prevalence of Salmonella spp. isolated from animal origin food items by conventional culture was $9.4 \%$ (18/192). A higher prevalence of $19.2 \%$ was observed in Gobessa town compared to the rest study settings but there was no significant association between the study sites and Salmonella spp. isolated from animal origin food items (Table 2).

3.2. A Chi-Square Analysis of the Putative Risk Factors Associated with Salmonella Occurrence in the Animal Origin Food Items. A Chi-square analysis revealed that catering establishments, protective clothing, source of contamination, manner of hand washing $(p<0.001)$, and money handling were significantly associated $(p<0.05)$ with Salmonella spp. occurrence among the putative risk factors considered during the study as indicated in Table 3.

3.3. Multivariable Logistic Regression Analysis of the Putative Risk Factors Associated with Salmonella spp. Occurrence in the Animal Origin Food Items. A logistic regression analysis of 
Table 1: Performance standards for antimicrobial susceptibility testing of Salmonella.

\begin{tabular}{|c|c|c|c|c|c|c|}
\hline No & Antimicrobial agent & Disc code & Potency $(\mu \mathrm{g})$ & Resistant & Intermediate & Susceptible \\
\hline 1 & Ampicillin & AMP & 10 & $\leq 13$ & $14-16$ & $\geq 17$ \\
\hline 2 & Amoxicillin-clavulanic acid & $\mathrm{AMC}$ & 30 & $\leq 13$ & $14-17$ & $\geq 18$ \\
\hline 3 & Ceftriaxone & $\mathrm{CRO}$ & 30 & $\leq 19$ & $20-22$ & $\geq 23$ \\
\hline 4 & Chloramphenicol & $\mathrm{CHL}$ & 30 & $\leq 12$ & $13-17$ & $\geq 18$ \\
\hline 5 & Ciprofloxacin & CIP & 5 & $\leq 20$ & $21-30$ & $\geq 31$ \\
\hline 6 & Gentamicin & $\mathrm{GN}$ & 10 & $\leq 12$ & $13-14$ & $\geq 15$ \\
\hline 7 & Kanamycin & KAN & 30 & $\leq 13$ & $14-17$ & $\geq 18$ \\
\hline 8 & Nalidixic acid & NA & 30 & $\leq 13$ & $14-18$ & $\geq 19$ \\
\hline 9 & Streptomycin & STR & 10 & $\leq 11$ & $12-14$ & $\geq 15$ \\
\hline 10 & Tetracycline & TTC & 30 & $\leq 11$ & $12-14$ & $\geq 15$ \\
\hline 11 & Trimethoprim-sulfamethoxazole & $\mathrm{W}$ & 5 & $\leq 10$ & $11-15$ & $\geq 16$ \\
\hline 12 & Sulphonamides & S3 & 300 & $\leq 12$ & $13-16$ & $\geq 17$ \\
\hline 13 & Nitrofurantoin & NTR & 50 & $\leq 14$ & $15-16$ & $\geq 17$ \\
\hline
\end{tabular}

Source: CLSI, (2016).

TABle 2: Overall prevalence of Salmonella isolated from selected type of animal origin food items in the study settings.

\begin{tabular}{|c|c|c|c|c|}
\hline \multirow[b]{2}{*}{ Variable category } & \multirow[b]{2}{*}{$\begin{array}{c}\text { Number of } \\
\text { sample tested }\end{array}$} & \multicolumn{2}{|c|}{ Result of tested sample number } & \multirow[b]{2}{*}{$\chi^{2}(p$ value $)$} \\
\hline & & $\begin{array}{c}\text { Negative sample } \\
\text { N (\%) }\end{array}$ & $\begin{array}{c}\text { Positive sample } \\
\text { N (\%) }\end{array}$ & \\
\hline \multicolumn{5}{|l|}{ Study settings } \\
\hline Dera & 36 & $32(88.9)$ & $4(11.1)$ & \\
\hline Iteya & 31 & $31(100)$ & $0(0)$ & \\
\hline Asella & 62 & $55(88.7)$ & $7(11.3)$ & $7.261(0.117)$ \\
\hline Bekoji & 37 & $35(94.6)$ & $2(5.4)$ & \\
\hline Gobessa & 26 & $21(80.8)$ & $5(19.2)$ & \\
\hline Total & 192 & $174(90.6)$ & $18(9.4)$ & \\
\hline
\end{tabular}

$\chi 2$, Pearson chi-square; N, Number of samples.

the putative risk factors indicated that consumers rinsing their hands with water only were more likely to be infected $(\mathrm{AOR}=14.203,95 \% \mathrm{CI}: 3.088,65.330)$ by Salmonella spp. pathogenic bacteria upon consuming animal origin food items than consumers using detergents and water while washing their hands as illustrated in Table 4.

\subsection{Occurrence of Salmonella in Animal Origin Food Items} and Its Antimicrobial Susceptibility. Antimicrobial susceptibility features of 18 Salmonella spp. isolated from different animal origin food items were subjected to 13 panels of antimicrobials to evaluate their resistant level. Among the panels of antimicrobial discs subjected to the isolates, ampicillin, nitrofurans, and sulphonamide resistance was significantly associated $(p<0.05)$ with Salmonella spp. occurrence in different types of animal origin food items. All (100\%) of the isolates obtained from "Dulet" were highly resistant to ampicillin, streptomycin, and nitrofurantoin while $6(85.7 \%), 4(57.1 \%)$, and 3 (42.8\%) of an isolates were resistant to kanamycin, gentamycin, and tetracycline, respectively. However, none of the isolates were resistant to ciprofloxacin, ceftriaxone, amoxicillin-clavulanic acid, nalidixic acid, sulphonamide, and trimethoprim-sulfamethoxazole which were isolated from "Dulet." Of the 4 isolates obtained from "Kitfo," all (100\%) of them were highly resistant to ampicillin and streptomycin while all of them were susceptible to gentamycin, ciprofloxacin, ceftriaxone, amoxicillin-clavulanic acid, nalidixic acid, sulphonamide, and trimethoprim-sulfamethoxazole. Pertaining to the 2 isolates obtained from the raw milk, both of them were highly resistant (100\%) to ampicillin, streptomycin, kanamycin, and tetracycline whereas both of the isolates subjected to a panel of antimicrobials were highly susceptible (100\%) to ciprofloxacin, ceftriaxone, amoxicillin-clavulanic acid, nalidixic acid, sulphonamide, and trimethoprim-sulfamethoxazole. Besides, interestingly, an isolate from egg sandwich was resistant to streptomycin, kanamycin, and nitrofurantoin while an isolate from cream cake was resistant to gentamycin, ampicillin, streptomycin, kanamycin, nitrofurantoin, and tetracycline as described in Table 5.

\subsection{Multiple Antimicrobial Resistance Profile of Salmonella} Species Isolated from Animal Origin Food Items. Out of 18 isolates from different animal origin food items in the selected study settings, all (100\%) of them were resistant to two or more panels of antibiotic discs. Of the isolates obtained from the current study, $3(16.7 \%), 5(27.8 \%), 5(27.8 \%)$, and 4 (22.2\%) were resistant to three, four, five, and six antibiotics, respectively, whereas only a single isolate was resistant to two antibiotics (viz. ampicillin and kanamycin) as revealed in Table 6. 
TABLE 3: A Chi-square analysis of association of the putative risk factors associated with Salmonella spp. prevalence in the animal origin food items in the selected study settings.

\begin{tabular}{|c|c|c|c|}
\hline Variables category & Number tested & $\mathrm{N}(\%)$ & $\chi^{2}(p$ value $)$ \\
\hline $\begin{array}{l}\text { Sample type } \\
\text { Kitfo } \\
\text { Kurt } \\
\text { Dulet } \\
\text { Egg sandwich } \\
\text { Raw milk } \\
\text { Cream cake }\end{array}$ & $\begin{array}{l}32 \\
32 \\
32 \\
32 \\
32 \\
32\end{array}$ & $\begin{array}{c}4(12.5) \\
3(9.4) \\
7(21.9) \\
1(3.1) \\
2(6.3) \\
1(3.1)\end{array}$ & $9.563(0.096)$ \\
\hline $\begin{array}{l}\text { Catering establishments } \\
\text { Hotel } \\
\text { Restaurant } \\
\text { Cafeteria } \\
\text { Retail shop } \\
\end{array}$ & $\begin{array}{c}14 \\
82 \\
87 \\
9\end{array}$ & $\begin{array}{l}4(28.6) \\
10(12.2) \\
3(3.45) \\
1(11.1)\end{array}$ & $10.469\left(0.016^{*}\right)$ \\
\hline $\begin{array}{l}\text { Protective clothing } \\
\text { Used } \\
\text { Not used }\end{array}$ & $\begin{array}{l}98 \\
94 \\
\end{array}$ & $\begin{aligned} & 15(15.3) \\
& 3(3.2) \\
&\end{aligned}$ & $8.288\left(0.004^{*}\right)$ \\
\hline $\begin{array}{l}\text { Source of contamination } \\
\text { Unclean cutting board\# } \\
\text { Dirty knife\# } \\
\text { Handling with unclean equipment and hands }\end{array}$ & $\begin{array}{c}22 \\
12 \\
158 \\
\end{array}$ & $\begin{array}{c}4(18.2) \\
3(25) \\
11(6.9) \\
\end{array}$ & $6.539\left(0.032^{*}\right)$ \\
\hline $\begin{array}{l}\text { Manner of hand washing } \\
\text { Rinsing with water only } \\
\text { Using detergents and water }\end{array}$ & $\begin{array}{c}41 \\
151 \\
\end{array}$ & $\begin{aligned} & 10(24.4) \\
& 8(5.3) \\
&\end{aligned}$ & $13.834\left(0.000^{* *}\right)$ \\
\hline $\begin{array}{l}\text { Money handling } \\
\text { Butcher with bare hand } \\
\text { Cashier } \\
\text { Service woman/man }\end{array}$ & $\begin{array}{c}14 \\
11 \\
167\end{array}$ & $\begin{array}{l}4(28.6) \\
2(18.2) \\
12(7.2)\end{array}$ & $8.019\left(0.020^{*}\right)$ \\
\hline $\begin{array}{l}\text { Cutting table (board) available } \\
\text { Single for minced meat } \\
\text { Separate for minced meat } \\
\text { Not available }\end{array}$ & $\begin{array}{l}85 \\
11 \\
96\end{array}$ & $\begin{array}{l}12(14.1) \\
2(18.2) \\
4(4.2)\end{array}$ & $6.320(0.053)$ \\
\hline $\begin{array}{l}\text { Origin of the sample } \\
\text { Dera } \\
\text { Iteya } \\
\text { Asella } \\
\text { Bekoji } \\
\text { Gobessa }\end{array}$ & $\begin{array}{l}36 \\
31 \\
62 \\
37 \\
26\end{array}$ & $\begin{array}{c}4(11.1) \\
0 \\
7(11.3) \\
2(5.4) \\
5(19.2)\end{array}$ & $7.261(0.117)$ \\
\hline
\end{tabular}

\#, for minced meat; $\mathrm{N}$, number of isolates; ${ }^{*}$, statistically significant; ${ }^{* *}$, statistically highly significant.

\section{Discussion}

Studies on the prevalence and antibiotic susceptibility profiles of Salmonella isolates from animal origin food items are scarce in Ethiopia. In the current study, the prevalence and the antimicrobial resistance profiles of Salmonella spp. isolated from foods of animal origin were evaluated. The study revealed that an overall prevalence rate of Salmonella spp. isolated from animal origin food items by conventional culture was $9.4 \%$ in the study areas. A higher prevalence rate of $19.2 \%$ was observed in Gobessa town compared to the rest study settings but there was no significant association between the study sites and Salmonella spp. isolated from animal origin food items.

Despite certain studies conducted on Salmonella isolation from animal origin food items in Ethiopia [13, 40-42], there had been no uniformity with respect to the sample type examined; as a result, overall prevalence of Salmonella in animal origin foods may not be comparable. Nevertheless, the overall prevalence of Salmonella in this study was lower than the report of [43] from selected African countries (19.9\%), [44] from Chinese food commodities (15.3\%) and [45] from Thailand retail foods (61\%), but higher than the reports of [13] from Gonder, Ethiopia (5.5\%), [46] from Morocco $(0.91 \%)$, and [47] from Lesotho $(0.72 \%)$. This variation could be due to the differences in the hygienic and sanitary practices of different catering establishments, equipment's used, method of cooking/boiling, the sample type, sampling procedures, and the detection methods employed in different studies.

A higher prevalence rate of Salmonella spp. (28.6\%) that had been isolated from animal origin food items was sampled from hotel among the catering establishments considered during the study period. This might be due to the limited sample size collected from hotels or the probability of food contamination in this catering was high due to poor 
TABLE 4: Multivariable logistic regression analysis of putative risk factors associated with Salmonella occurrence in animal origin food in the selected study areas.

\begin{tabular}{|c|c|c|c|c|c|}
\hline \multirow{2}{*}{ Variables category } & \multirow{2}{*}{$\begin{array}{l}\text { Number of tested } \\
\text { samples }\end{array}$} & \multirow{2}{*}{$\begin{array}{c}\text { Number of positive samples } \\
\mathrm{N}(\%)\end{array}$} & \multicolumn{2}{|c|}{ Odds ratio } & \multirow{2}{*}{$p$ value } \\
\hline & & & COR $(95 \% \mathrm{CI})$ & AOR $(95 \% \mathrm{CI})$ & \\
\hline \multicolumn{6}{|l|}{ Catering establishments } \\
\hline Hotel & 14 & $4(28.6)$ & $\mathrm{R}$ & $\mathrm{R}$ & \multirow{4}{*}{0.059} \\
\hline Restaurant & 82 & $10(12.1)$ & $\begin{array}{l}3.2(0.296 \\
34.588)\end{array}$ & $\begin{array}{c}5.048(0.274 \\
93.105)\end{array}$ & \\
\hline Cafeteria & 87 & $3(3.45)$ & $1.1(0.125,9.844)$ & $\begin{array}{l}4.674(0.300 \\
72.868)\end{array}$ & \\
\hline Retail shop & 9 & $1(11.1)$ & $\begin{array}{c}0.286(0.027 \\
3.076)\end{array}$ & $\begin{array}{l}0.348(0.025 \\
4.772)\end{array}$ & \\
\hline \multicolumn{6}{|l|}{ Protective clothing } \\
\hline Used & 98 & $15(15.3)$ & $\begin{array}{c}5.482(1.532 \\
19.614)\end{array}$ & $\begin{array}{c}7.171(1.603 \\
32.083)\end{array}$ & \multirow[t]{2}{*}{$0.010^{*}$} \\
\hline Not used & 94 & $3(3.2)$ & $\mathrm{R}$ & $\mathrm{R}$ & \\
\hline \multicolumn{6}{|l|}{ Source of contamination } \\
\hline Unclean cutting board & 22 & $4(18.2)$ & $\mathrm{R}$ & $\mathrm{R}$ & \multirow{3}{*}{0.551} \\
\hline Dirty knife & 12 & $3(25)$ & $\begin{array}{c}2.970(0.855 \\
10.310)\end{array}$ & $\begin{array}{l}0.559(0.094 \\
3.332)\end{array}$ & \\
\hline $\begin{array}{l}\text { Handling with unclean equipment } \\
\text { and hands }\end{array}$ & 158 & $11(6.9)$ & $\begin{array}{c}4.455(1.052 \\
18.861) \\
\end{array}$ & $\begin{array}{l}1.846(0.325 \\
10.492)\end{array}$ & \\
\hline \multicolumn{6}{|l|}{ Manner of hand washing } \\
\hline Using detergents and water & 41 & $10(24.4)$ & $\mathrm{R}$ & $\mathrm{R}$ & \multirow{2}{*}{$0.001^{* *}$} \\
\hline Rinsing with water only & 151 & $8(5.3)$ & $\begin{array}{c}5.766(2.105 \\
15.792)\end{array}$ & $\begin{array}{c}14.203(3.088 \\
65.330)\end{array}$ & \\
\hline \multicolumn{6}{|l|}{ Money handling } \\
\hline Butcher with bare hand & 14 & $4(28.6)$ & $\mathrm{R}$ & $\mathrm{R}$ & \multirow{3}{*}{0.990} \\
\hline Cashier & 11 & $2(18.2)$ & $\begin{array}{c}5.167(1.408 \\
18.954)\end{array}$ & $\begin{array}{l}0.998(0.151 \\
6.479)\end{array}$ & \\
\hline Service woman/man & 167 & $12(7.2)$ & $\begin{array}{c}2.870(0.556 \\
14.810)\end{array}$ & $\begin{array}{c}1.016(0.099 \\
10.418)\end{array}$ & \\
\hline
\end{tabular}

$\mathrm{AOR}$, adjusted odds ratio; $\mathrm{COR}$, crude odds ratio; $\mathrm{CI}$, confidence interval; $R$, reference.

sanitary conditions of the establishment and improper handling practice of food. Thus, health hazards from catering establishments may be minimized by avoiding poor handling and awareness of personal hygiene and care in preparation, storage, and dispensing of foods in all procedures necessary to maintain the safety and suitability of food from the establishments, appropriate solid and liquid waste collection and disposal should be planned and implemented and periodic sanitary-hygienic evaluation, and inspection of catering establishments should be strengthened to reduce public health hazards associated with food-borne pathogens using systems such as HACCP [48].

Though most of the food handlers/servants used protective clothes during dinning time, about $15.3 \%$ of Salmonella isolates were obtained from the samples handled by servants using protective clothing which is inconsistent with the report of [48]. This needs an indepth study to unveil the factors responsible for the occurrence of the pathogen.

Approximately $25 \%$ incidence rate of Salmonella observed in the current study from minced meat prepared using dirty cutting knife was higher than that reported from Gondar [11] and Mojo [49], Ethiopia, and slightly lower than the reports from Botswana abattoir [50]. The current high prevalence recorded from minced meat prepared by cutting knife might be due to poor hygienic condition of knives and/ or high prevalence of Salmonella in meat samples which might act as a source of contamination for the knives.

The odds ratio of being positive for Salmonella spp. isolation is 14.203 times higher among food handlers who rinsed their hands with water only compared to those who washed their hands with water and detergents. This finding corroborates with earlier studies conducted elsewhere in Ethiopia [51-53]. Personal hygiene differences of the food handlers might help to explain this discrepancy since majority of the workers in the current investigation settings practiced very poor hand washing. Improvement of food worker hand washing practices, the least costly intervention to implement, is critical to the reduction of food-borne illness $[11,54]$.

The occurrence of Salmonella in the minced meat (Kitfo, Kurt, and Dulet) in contact with bare handed butcher man in this study was $28.6 \%$, which was higher than an isolate obtained from cashier or service woman/man in contact with the sample in the current study. This is attributed to simultaneous handling of food and money which increases the risk of cross contamination [55].

In the current study, though not significant, the highest prevalence of Salmonella was isolated from raw "Dulet" (fried meat) (21.9\%) as compared to raw "Kitfo" (minced meat) and "Kurt" (chopped meat consumed with or without 
TABLE 5: The general proportion of antimicrobial susceptibility test among Salmonella isolates from the selected animal origin food items in the study sites.

\begin{tabular}{|c|c|c|c|c|c|c|c|}
\hline \multirow[b]{2}{*}{$\begin{array}{l}\text { Antimicrobials } \\
\text { tested }\end{array}$} & \multicolumn{6}{|c|}{ Types of sample tested } & \multirow{3}{*}{$\chi^{2}(p$-value $)$} \\
\hline & $\begin{array}{c}\text { Kitfo (\%) } \\
\quad N=4\end{array}$ & $\begin{array}{l}\text { Kurt }(\%) \\
\quad N=3\end{array}$ & $\begin{array}{l}\text { Dulet }(\%) \\
\quad N=7\end{array}$ & $\begin{array}{l}\text { Egg Sandwich (\%) } \\
\qquad N=1\end{array}$ & $\begin{array}{c}\text { Raw } \\
\text { milk (\%) } \\
N=2\end{array}$ & $\begin{array}{l}\text { Cream cake }(\%) \\
\qquad N=1\end{array}$ & \\
\hline \multirow{2}{*}{\multicolumn{8}{|c|}{$n=32$ for all samples }} \\
\hline & & & & & & & \\
\hline Sensitive & $4(100)$ & $1(33.3)$ & $2(28.6)$ & $1(100)$ & $1(50)$ & 0 & \multirow{3}{*}{$20.730(0.102)$} \\
\hline Intermediate & 0 & 0 & $1(14.3)$ & 0 & 0 & 0 & \\
\hline Resistant & 0 & $2(66.7)$ & $4(57.1)$ & 0 & $1(50)$ & $1(100)$ & \\
\hline \multicolumn{8}{|l|}{ Ciprofloxacin } \\
\hline Sensitive & $4(100)$ & $3(100)$ & $7(100)$ & $1(100)$ & $\begin{array}{c}2 \\
(100)\end{array}$ & $1(100)$ & \multirow{3}{*}{$9.563(0.093)$} \\
\hline Intermediate & 0 & 0 & 0 & 0 & 0 & 0 & \\
\hline Resistant & 0 & 0 & 0 & 0 & 0 & 0 & \\
\hline \multicolumn{8}{|l|}{ Ceftriaxone } \\
\hline Sensitive & $4(100)$ & $3(100)$ & $7(100)$ & $1(100)$ & $\begin{array}{c}2 \\
(100)\end{array}$ & $1(100)$ & \multirow{3}{*}{$9.563(0.093)$} \\
\hline Intermediate & 0 & 0 & 0 & 0 & 0 & 0 & \\
\hline Resistant & 0 & 0 & 0 & 0 & 0 & 0 & \\
\hline \multicolumn{8}{|l|}{ Ampicillin } \\
\hline Sensitive & 0 & 0 & 0 & 0 & 0 & 0 & \multirow{3}{*}{$\begin{array}{c}16.779 \\
\left(0.038^{*}\right)\end{array}$} \\
\hline Intermediate & 0 & 0 & 0 & $1(100)$ & 0 & 0 & \\
\hline Resistant & $4(100)$ & $3(100)$ & $7(100)$ & $0(0)$ & $\begin{array}{c}2 \\
(100)\end{array}$ & $1(100)$ & \\
\hline \multicolumn{8}{|l|}{ Streptomycin } \\
\hline Sensitive & 0 & 0 & 0 & 0 & 0 & 0 & \multirow{3}{*}{$9.563(0.093)$} \\
\hline Intermediate & 0 & 0 & 0 & 0 & 0 & 0 & \\
\hline Resistant & $4(100)$ & $3(100)$ & $7(100)$ & $1(100)$ & $\begin{array}{c}2 \\
(100)\end{array}$ & $1(100)$ & \\
\hline
\end{tabular}

TABLE 6: Multiple antimicrobial resistance profile of Salmonella isolates from animal origin food items in the selected catering establishments of the study areas.

\begin{tabular}{lcc}
\hline Number of antimicrobial resistance & Antimicrobial resistance patterns (\#) & Number of isolates (\%) $(n=18)$ \\
\hline Two & AMP, KAN (1) & $1(5.6)$ \\
Three & AMP, STR, KAN (1) & $3(16.7)$ \\
& AMP, STR, NTR (1) & STR, KAN, NTR (1) \\
Four & AMP, STR, NTR, TTC (1) & $5(27.8)$ \\
& GN, AMP, STR, KAN (1) & $5(27.8)$ \\
\hline \multirow{2}{*}{ Five } & GN, AMP, STR, NTR (1) \\
& AMP, STR, KAN, NTR (2) & \\
\hline Six & GN, AMP, STR, KAN, NTR (2) & $4(22.2)$ \\
\hline Total & AMP, STR, KAN, NTR, TTC (2) \\
\hline
\end{tabular}

GN, gentamycin; AMP, ampicillin; KAN, kanamycin; STR, streptomycin; NTR, nitrofurans; TTC, tetracycline; CHL, chloramphenicol; \#, number of isolates which is resistant to a group of antibiotics.

"Berbere" or "Mitmita"). This could be due to no clear division of slaughtering process: stunning, bleeding, skinning, evisceration, hanging, and cutting/deboning. Furthermore, there was no preventive mechanism installed for insects and rodents in abattoir/back yard slaughtering where sheep and goat rumen and reticulum are evacuated and cleaned with running water which is similar with the report of $[56,57]$ from abattoir and butcher shops of Mekele and Bishoftu towns of Ethiopia, respectively. On top of this, this might be due to the fact that many people in Ethiopia also recognize the richness of liver in nutrients and consume it raw with hot pepper or spices. Thus, it is reasonable to assume that meat, 
milk, and liver can serve as vehicles for extensive transmission of Salmonella to humans [18].

The frequency of isolation of Salmonella from raw "Kitfo" in this study was $12.5 \%$. This finding is comparable with the report of [41] (12.1\%) from retail meat products and [42] (14.4\%) from minced beef in Ethiopia. However, it is much lower than the report of [58] (42\%) from "Kitfo," a traditional Ethiopian spiced, minced meat dish. In contrary to this, our finding is higher than the studies conducted by [40] (7.9\%) and [59] (8\%) on minced beef in Ethiopia and it is also much higher than $1.8 \%, 2.0 \%$, and $5.3 \%$ of minced meat reported from USA, England, and Germany, respectively [60]. A relatively higher prevalence rate in this study could be attributed to the mincing process in "Kitfo" preparation which guaranteed contamination of new surface areas.

The constant isolation of Salmonella from some food establishments in the current study indicated that these establishments could have constant sources of contamination with Salmonella. Food handlers, who may be carriers of Salmonella, are definite sources of contamination if they are not following basic hygienic principles during food handling. Other possible sources of contamination could be cutting boards, which could harbor Salmonella, as they are not cleaned thoroughly and are usually moist. Salmonellae may establish a niche in a crack in these woody cutting boards, proliferate, and continue to contaminate whatever comes in contact with the cutting board as indicated by [58] in their study. In this study, observation of the kitchen environments in the food establishments showed that the hygienic condition of the kitchens and the food handlers in most cases was very unsatisfactory.

Among the raw minced meat considered in the present study, low prevalence (9.4\%) of Salmonella was obtained from chopped "Kurt" with or without "Berbere" (Ethiopian seasoning prepared from dry red chili peppers, garlic, and other spices) or "Mitmita" (Bird's eye red pepper spiced with cardamom and salt). The traditional way of eating these foods with fingers might contribute to the contamination of the foods with Salmonella. In the category of egg Sandwich, we recorded a contamination rate of $3.1 \%$ which is inconsistent with the report of [13] from Gondar, in which no isolate was recorded.

Salmonella detection from raw milk (6.3\%) in this study was comparable with a study conducted in Nigeria [61] and lower than 20\% prevalence rate in Ethiopia [62]. This difference might arise from milking contamination, unclean equipment, and poor hygiene of milkmaid and handlers. However, it is higher than the prevalence of $2.1 \%$, which is found in Ethiopia [63]. As indicated by [64], unclean environmental conditions and poor udder preparation might expose raw milk to bacterial contamination.

Custard cake products in Ethiopia are usually called cream cakes possibly due to the creamy nature of the custard. Though there are large numbers of custard cake consumers among the urban community in Ethiopia, the safety and quality of these products have rarely been assessed. Only a single (3.1\%) Salmonella isolate was obtained from the cream cakes considered in this work, which is inconsistent with the report of [13] in which no isolate was recorded. A study conducted by [65] revealed that pastry products were among the major food vehicles for outbreaks of Salmonella spp. and were responsible for $16.6 \%$ of outbreaks in Rio Grande do Sul state, during the periods of 1997 to 1999. The frequency of isolation of Salmonella from cream cake (custard cake) in the current study was lower than that recorded in Addis Ababa (10\%) [66]. Contamination of custard cakes with Salmonella might have arisen from contaminated eggs used for custard preparation and/or Salmonella carriers among food handlers. Since custard provides a fertile growth medium, keeping custard cakes for several hours at ambient temperature may support the growth of Salmonellae.

Resistance for two or more of antimicrobials (100\%) which was observed in this study was higher than other studies conducted in Ethiopia $[59,67,68]$ and elsewhere in the world $[69,70]$. This difference may be due to the increasing rate of inappropriate utilization of antibiotics in farm animals which favors selection pressure that increased the advantage of maintaining resistance genes in bacteria [28]. In recent times, the frequency of antimicrobial drug resistance in Salmonella and the number of drugs to which the strains are resistant have increased worldwide, primarily as a consequence of antimicrobial use in food production. Recent reports have also highlighted the emergence of Salmonella with reduced susceptibility to fluoroquinolones and other drugs [26], which is associated with treatment failures and poor outcomes in human infections.

Zewdu and Cornelius [59] reported that the isolates of Salmonella from food items and personnel from Addis Ababa were resistant to the commonly used antibiotics including streptomycin, ampicillin, and tetracycline. The result of the current research also indicated resistance of Salmonella isolates to commonly used antimicrobials including streptomycin, ampicillin, nitrofurantoin, kanamycin, and tetracycline, with resistance rate of $100 \%, 94.4 \%$, $77.8 \%, 77.8 \%$, and $44.4 \%$, respectively. Salmonella resistance in this finding is higher than the previous studies conducted in Ethiopia [59, 62], and other countries [71, 72]. The remarkable rise in the occurrence of antimicrobial resistance in Salmonella for the mentioned antibiotics was probably an indication of their frequent usage both in livestock and in public health sectors in Ethiopia. Studies conducted elsewhere in Ethiopia [73] have also indicated that the increase in the proportion of drug-resistant Salmonella isolates could be due to the irrational use of antimicrobials and inappropriateness of the prescription and dispensing methods in both the public veterinary and private health setups of the country [13].

In the current study, all of the isolates obtained from different animal origin food items (100\%) were resistant streptomycin which is consistent with the report of [18] from bovine or ovine isolates of Salmonella in Ethiopia. Thus, it is of significant concern, since our study involves all randomly selected samples. Resistance of Salmonella from food items, animals, and humans to streptomycin was reported by several studies in Ethiopia [14, 59, 67, 74, 75] but the level of 
resistance to streptomycin ranged from 46 to $86 \%$. This extremely high level of resistance of Salmonella and other pathogens (e.g., similar high level resistance to streptomycin has also been reported in Ethiopian tuberculosis patients, including in newly diagnosed patients [76] and references therein) to streptomycin in Ethiopia should be cause for high concern as it might also cause cross resistance to other drugs with similar mechanism of action.

Due to the relatively limited access and high price to get the newly developed cephalosporin and quinolone drugs, the reports of prevalence of antimicrobial-resistant Salmonella to relatively low-priced and regularly available antibiotics are alarming for a low-income society living in most developing countries, like Ethiopia. However, it is important to note that these antibiotics are commonly used in veterinary medicine, and infections with these resistant Salmonella isolates could lower the efficiency of antibiotic treatment [18].

\section{Conclusion}

The current study revealed that Salmonella isolates were identified from animal origin food items, viz. raw/minced meat ("Kitfo", "Kurt," and "Dulet"), raw milk, egg sandwich, and cream cake, in the selected areas of Arsi zone. Catering establishments, protective clothing, source of contamination, manner of hand washing, and money handling were among the putative risk factors that were significantly associated with Salmonella spp. incidence in the selected food items. A high proportion of Salmonella isolates resistant to two or more panels of antimicrobials in this study implies a significant public health risk of consuming raw/minced animal origin food items-associated with salmonellosis occurrence. In conclusion, the general sanitary condition of the catering establishments, utensils used, and personnel hygienic practices were not to the recommended standards in the current study. Besides, detection of multidrug-resistant strains of Salmonella in animal origin food items from different catering establishments suggests the need for detailed epidemiological and molecular characterization of the pathogen so as to establish the sources of acquisition of resistant Salmonella strains. Hence, implementation of Salmonella prevention and control strategies from farm production to consumption of animal origin food items are crucial.

\section{Data Availability}

The data used to support the findings of this study are available from the corresponding author upon request.

\section{Conflicts of Interest}

The authors declare that they have no conflicts of interest.

\section{Acknowledgments}

The authors would like to thank all different catering establishments' workers who participated in this study. The authors also acknowledge Research and Publication Directorate of Arsi University for the grant award in order to accomplish their research work successfully. Moreover, the authors gratefully thank Asella Regional Laboratory for material and laboratory work support.

\section{Supplementary Materials}

All the isolates obtained from the selected food of animal origin were confirmed primarily with the help of Salmonella spp. growth and morphological characteristics on xylose lysine deoxycholate (XLD) (Figure S1) and then with biochemical tests (Figures S2-S7) and antimicrobial susceptibility test (Figure S8). (Supplementary Materials)

\section{References}

[1] A. Assefa and A. Bihon, "A systematic review and metaanalysis of prevalence of Escherichia coli in foods of animal origin in Ethiopia," Heliyon, vol. 4, no. 8, pp. 1-22, 2018.

[2] H. Legese, T. Kahsay, A. Gebrewahd et al., "Prevalence, antimicrobial susceptibility pattern, and associated factors of Salmonella and Shigella among food handlers in Adigrat University student's cafeteria, Northern Ethiopia, 2018," Tropical Diseases, Travel Medicine and Vaccines, vol. 6, p. 19, 2020.

[3] WHO, "Food safety," in Fact SheetWorld Health Organization, Geneva, Switzerland, Available online: https://www.who. $\mathrm{int} /$ news-room/fact-sheets/detail/food-safety, 2019.

[4] K. Diriba, E. Awulachew, and Z. Ashuro, "Prevalence and antimicrobial resistance pattern of Salmonella, Shigella, and intestinal parasites and associated factor among food handlers in Dilla University student cafeteria, Dilla, Ethiopia," International Journal of Microbiology, vol. 2020, p. 10, Article ID 3150539, 2020.

[5] D. Faour-Klingbeil and E. Todd, "Prevention and control of foodborne diseases in middle-east north african countries: review of national control systems," International Journal of Environmental Research and Public Health, vol. 17, no. 1, p. 70, 2020.

[6] D. A. Mengistu and S. T. Tolera, "Prevalence of microorganisms of public health significance in ready-to-eat foods sold in developing countries: systematic review and metaanalysis," International Journal of Food Science, vol. 2020, Article ID 8867250, 9 pages, 2020.

[7] WHO, Regional Office for Africa "Developing and Maintaining Food Safety Control Systems for Africa: Current Status and Prospects for Change", pp. 12-14, Second FAO/WHO Global Forum of Food Safety Regulators, Bangkok, Thailand, 2004.

[8] W. Wabeto, Y. Abraham, and A. A. Anjulo, "Detection and identification of antimicrobial-resistant Salmonella in raw beef at Wolaita Sodo municipal abattoir, Southern Ethiopia," Journal of Health, Population and Nutrition, vol. 36, no. 1, p. 52, 2017.

[9] CDC, "Surveillance for foodborne disease outbreaks-United States, 2008," Morbidity and Mortality Weekly Report, vol. 59, no. 31, pp. 1277-1280, 2010.

[10] F. K. Käferstein, "Food safety as a public health issue for developing countries," in Focus 10, Brief 2. 2020 Vision for Food, Agriculture and the EnvironmentInternational Food Policy Research Institute, Washington, DC, USA, 2003.

[11] L. Garedew, Z. Hagos, Z. Addis, R. Tesfaye, and B. Zegeye, "Prevalence and antimicrobial susceptibility patterns of Salmonella isolates in association with hygienic status from 
butcher shops in Gondar town, Ethiopia," Antimicrobial Resistance and Infection Control, vol. 4, p. 21, 2015.

[12] E. Carrasco, A. Morales-Rueda, and R. M. García-Gimeno, "Cross-contamination and recontamination by Salmonella in foods: a review," Food Research International, vol. 45, no. 2, pp. 545-556, 2012.

[13] M. Ejo, L. Garedew, Z. Alebachew, and W. Worku, "Prevalence and antimicrobial resistance of Salmonella isolated from animal origin food items in Gondar, Ethiopia," BioMed Research International, vol. 2016, Article ID 4290506, 8 pages, 2016.

[14] T. Eguale, W. A. Gebreyes, D. Asrat, H. Alemayehu, J. S. Gunn, and E. Engidawork, "Non-typhoidal Salmonella serotypes, antimicrobial resistance and co-infection with parasites among patients with diarrhea and other gastrointestinal complaints in Addis Ababa, Ethiopia," BMC Infectectious Disease, vol. 15, p. 497, 2015.

[15] D. A. Galgallo, Z. G. Roka, W. G. Boru, K. Abill, and J. Ransom, "Investigation of a typhoid fever epidemic in Moyale Sub-County, Kenya, 2014-2015," Journal of Health, Population and Nutrition, vol. 37, no. 1, p. 14, 2018.

[16] C. O. A. Omwandho and T. Kubota, "Salmonella enterica serovar enteritidis: a mini-review of contamination routes and limitations to effective control," Japan Agricultural Research Quarterly: JARQ, vol. 44, no. 1, pp. 7-16, 2010.

[17] H. Sharkawy, A. Tahoun, A. E. G. A. El-Gohary et al., "Epidemiological, molecular characterization and antibiotic resistance of Salmonella enterica serovars isolated from chicken farms in Egypt," Gut Pathogens, vol. 9, p. 8, 2017.

[18] A. Kebede, J. Kemal, H. Alemayehu, and S. Habte Mariam, "Isolation, identification and antibiotic susceptibility testing of Salmonella from slaughtered bovines and ovines in Addis Ababa Abattoir Enterprise, Ethiopia: a cross-sectional study," International Journal of Bacteriology, vol. 2016, Article ID 3714785, 8 pages, 2016.

[19] L. Ketema, Z. Ketema, B. Kiflu et al., "Prevalence and antimicrobial susceptibility profile of Salmonella serovars isolated from slaughtered cattle in Addis Ababa, Ethiopia," BioMed Research International, vol. 2018, Article ID 9794869, 7 pages, 2018.

[20] T. Eguale, D. Asrat, H. Alemayehu et al., "Phenotypic and genotypic characterization of temporally related nontyphoidalSalmonellastrains isolated from humans and food animals in central Ethiopia," Zoonoses and Public Health, vol. 65, no. 7, pp. 766-776, 2018.

[21] B. Dagnew, H. Alemayehu, G. Medhin, and T. Eguale, "Prevalence and antimicrobial susceptibility of Salmonella in poultry farms and in-contact humans in Adama and Modjo towns, Ethiopia," Microbiology Open, vol. 9, Article ID e1067, 2020 .

[22] A. E. Mather, S. W. J. Reid, D. J. Maskell et al., "Distinguishable epidemics of multidrug-resistant Salmonella typhimurium DT104 in different hosts," Science, vol. 341, no. 6153, pp. 1514-1517, 2013.

[23] X. Wang, S. Biswas, N. Paudyal et al., "Antibiotic resistance in Salmonella typhimurium isolates recovered from the food chain through national antimicrobial resistance monitoring system between 1996 and 2016," Frontiers in Microbiology, vol. 10, p. 985, 2019.

[24] S. Takele, K. Woldemichael, M. Gashaw, H. Tassew, M. Yohannes, and A. Abdissa, "Prevalence and drug susceptibility pattern of Salmonella isolates from apparently healthy slaughter cattle and personnel working at the Jimma municipal abattoir, South-West Ethiopia," Tropical Diseases, Travel Medicine and Vaccines, vol. 4, p. 13, 2018.

[25] T. Eguale, "Non-typhoidal Salmonella serovars in poultry farms in central Ethiopia: prevalence and antimicrobial resistance," BMC Veterinary Research, vol. 14, no. 1, p. 217, 2018.

[26] WHO, Antimicrobial Resistance: Global Report on Surveillance, p. 257, WHO, Geneva, Switzerland, 2014.

[27] S. Omulo, S. M. Thumbi, M. K. Njenga, and D. R. Call, "A review of 40 years of enteric antimicrobial resistance research in Eastern Africa: what can be done better?" Antimicrobial Resistance and Infection Control, vol. 4, p. 1, 2015.

[28] Z. Addis, N. Kebede, Z. Sisay, H. Alemayehu, A. Yirsaw, and T. Kassa, "Prevalence and antimicrobial resistance of Salmonella isolated from lactating cows and in contact humans in dairy farms of Addis Ababa: a cross sectional study," BMC Infectious Disease, vol. 11, p. 222, 2011.

[29] G. Beyene, S. Nair, D. Asrat, Y. Mengistu, H. Engers, and J. Wain, "Multidrug resistant Salmonella concord is a major cause of salmonellosis in children in Ethiopia," The Journal of Infection in Developing Countries, vol. 5, no. 01, pp. 023-033, 2011.

[30] T. Eguale, J. Birungi, D. Asrat et al., "Genetic markers associated with resistance to beta-lactam and quinolone antimicrobials in non-typhoidal Salmonella isolates from humans and animals in central Ethiopia," Antimicrobial Resistance and Infection Control, vol. 6, p. 13, 2017.

[31] K. G. Jagiso, L. T. Wodajo, and S. Yusu, "Contraceptive utilization among couples and associated factors in Dodota district, Oromia Region, Ethiopia," Biomedical Journal of Scientific and Technical Research, vol. 4, no. 1, Article ID 000986, 2018.

[32] M. Hussein, M. Melaku, and T. Bekele, "Study on prevalence and identification of bovine tick species in Hetosa district of East Arsi Zone, Eastern Ethiopia," International Journal of Advanced Research in Biological Sciences, vol. 5, no. 7, pp. 105-114, 2018.

[33] H. Waktole, M. Almaw, D. Taweya et al., "Opportunities and challenges of indigenous chicken in Asella district, Arsi zone, Oromia, Ethiopia: implications for designing improved productivity schemes," Journal Bacteriology and Mycology: Open Access, vol. 6, no. 3, pp. 229-235, 2018.

[34] Bekoji Town Municipality Report, Lemu Bilbilo District Administrative Center Human Population Report, Bekoji Town Municipality Report, Bekoji, Ethopia, 2018.

[35] Shirka Woreda Agricultural and Rural Development Office Report, 2018.

[36] M. Thrusfield, Sampling in Veterinary Epidemiology, Black well Science Ltd, vol. 46-65pp. 228-242, London, UK, 3rd edition, 2008.

[37] ISO-6579, Microbiology Of Food And Animal Feeding Stuffs: Horizontal Method For The Detection Of Salmonella Spp, vol. 2002, pp. 511-525, ISO, Geneva, Switzerland, 2002.

[38] GSS and WHO, A Global Salmonella Surveillance and Laboratory Support Project of the WHO, Laboratory Protocols Level 1 Training Course Identification of Salmonella, WHO, Geneva, Switzerland, 4th edition, 2003.

[39] CLSI, Performance Standards for Antimicrobial Susceptibility Testing; Twenty-Sixth Informational Supplement. CLSI Document M100-S26, Clinical and Laboratory Standards Institute, Wayne, PA, USA, 2016.

[40] C. Nyeleti, B. Molla, G. Hildebrandt, and J. Kleer, "The prevalence and distribution of Salmonellae in slaughter cattle, slaughterhouse personnel and minced beef in Addis Ababa 
(Ethiopia)," Bulletin of Animal Health and Production in Africa, vol. 48, pp. 19-24, 2000.

[41] B. Molla, D. Alemayehu, and W. Salah, "Sources and distribution of Salmonella serotypes isolated from food animals, slaughterhouse personnel and retail meat products in Ethiopia: 1997-2002," Ethiopian Journal of Health Development, vol. 17, p. 1, 2003.

[42] G. Ejeta, B. Molla, D. Alemayehu, and A. Muckle, "Salmonella serotypes isolated from minced meat beef, mutton and pork in Addis Ababa, Ethiopia," Revue de Medecine Veterinaire, vol. 155, no. 11, pp. 547-551, 2004.

[43] N. Paudyal, H. Pan, X. Liao et al., "A meta-analysis of major foodborne pathogens in Chinese food commodities between 2006 and 2016," Foodborne Pathogens and Disease, vol. 15, no. 4, p. 187, 2018.

[44] N. Paudyal, V. Anihouvi, J. Hounhouigan et al., "Prevalence of foodborne pathogens in food from selected African countries - a meta-analysis," International Journal of Food Microbiology, vol. 249, pp. 35-43, 2017.

[45] S. M. Vindigni, A. Srijan, B. Wongstitwilairoong et al., "Prevalence of foodborne microorganisms in retail foods in Thailand," Foodborne Pathogens and Disease, vol. 4, no. 2, pp. 208-215, 2007.

[46] B. Bouchrif, B. Paglietti, M. Murgia et al., "Prevalence and antibiotic-resistance of Salmonella isolated from food in Morocco," Journal of Infection in Developing Countries, vol. 3 , no. 1, pp. 35-40, 2009.

[47] T. M. Seeiso and C. M. E. McCrindle, "An investigation of the quality of meat sold in Lesotho," Journal of the South African Veterinary Association, vol. 80, pp. 237-242, 2009.

[48] M. Haileselassie, H. Taddele, and K. Adhana, "Source(s) of contamination of 'raw' and 'ready-to-eat' foods and their public health risks in Mekelle City, Ethiopia," ISABB Journal of Food and Agricultural Science, vol. 2, no. 2, pp. 20-29, 2012.

[49] T. Akafete and N. Haileleul, "Assessment of risk factors and prevalence of Salmonella in slaughtered small ruminants and environment in an export abattoir, Modjo, Ethiopia," American-eurasian Journal of Agriculture and Environmental Science, vol. 10, no. 6, pp. 992-999, 2011.

[50] C. Motsoela, E. K. Collison, and B. A. Gashe, "Prevalence of Salmonella in two Botswana abattoir environments," Journal of Food Protection, vol. 65, no. 12, pp. 1869-1872, 2002.

[51] D. Nigusse and A. Kumie, "Food hygiene practices and prevalence of intestinal parasites among food handlers working in Mekelle University students' cafeteria," Mekelle Global Advanced Research Journal of Social Science, vol. 1, no. 4, pp. 65-71, 2012.

[52] D. Marami, K. Hailu, and M. Tolera, "Prevalence and associated factors of intestinal parasitic infections among asymptomatic food handlers working at Haramaya University cafeterias, eastern Ethiopia," Annals of Occupational and Environmental Medicine, vol. 30, p. 53, 2018.

[53] A. Kumalo, E. Gambura, T. Dodicho et al., "Prevalence of intestinal parasites and Salmonella typhi among food handlers working in catering establishments of public institutes found in Dawuro Zone, South-Western Ethiopia," Journal of Parasitology Research, vol. 2021, Article ID 8889302, 10 pages, 2021.

[54] L. R. Green, C. A. Selman, V. Radke et al., "Food worker hand washing practices: an observation study," Journal of Food Protection, vol. 69, no. 10, pp. 2417-2423, 2006.

[55] M. U. Ukwuru and A. Gabriel, "Cross contamination between food and money due to simultaneous handling," Journal of
Applied Science and Environmental Management, vol. 3, pp. 42-48, 2012.

[56] M. Haileselassie, H. Taddele, K. Adhana, and S. Kalayou, "Food safety knowledge and practices of abattoir and butchery shops and the microbial profile of meat in Mekelle city, Ethiopia," Asian Pacific Journal of Tropical Biomedicine, vol. 3, no. 5, pp. 407-412, 2013.

[57] A. Bersisa, D. Tulu, and C. Negera, "Investigation of bacteriological quality of meat from abattoir and butcher shops in Bishoftu, Central Ethiopia," International Journal of Microbiology, vol. 2019, Article ID 6416803, 8 pages, 2019.

[58] M. Tegegne and M. Ashenafi, "Microbial load and incidence of Salmonella spp.in 'Kitfo', a traditional Ethiopian spiced, minced meat dish," Ethiopian Journal of Health Development, vol. 12, no. 2, pp. 135-140, 1998.

[59] E. Zewdu and P. Cornelius, "Antimicrobial resistance pattern of Salmonella serotypes isolated from food items and personnel in Addis Ababa, Ethiopia," Tropical Animal Health and Production, vol. 41, no. 2, pp. 241-249, 2009.

[60] D. K. O'Toole, “Technical report: microbiological quality of pork meat from local Hong Kong markets," World Journal of Microbiology and Biotechnology, vol. 11, pp. 699-702, 1995.

[61] N. S. Karshima, V. A. Pam, S.I. Bata, P. A. Dung, and N. D. Paman, "Isolation of Salmonella species from milk and locally processed milk products traded for human consumption and associated risk factors in Kanam, Plateau State, Nigeria," Journal of Animal Production Advances, vol. 3, no. 3, pp. 69-74, 2013.

[62] T. Tadesse and A. Dabassa, "Prevalence and antimicrobial resistance of Salmonella isolated from raw milk samples collected from Kersa district, Jimma Zone, Southwest Ethiopia," Journal of Medical Sciences, vol. 12, no. 7, pp. 224-228, 2012.

[63] T. Liyuwork, T. Biruhalem, A. Sefinew, A. Haile, S. Zufan, and N. Haileleul, "Prevalence and antimicrobial resistance profile of Salmonella isolates from dairy products in Addis Ababa, Ethiopia," African Journal of Microbiology Research, vol. 7, no. 43, pp. 5046-5050, 2013.

[64] L. Garedew, A. Berhanu, D. Mengesha, and G. Tsegay, "Identification of gram-negative bacteria from critical control points of raw and pasteurized cow milk consumed at Gondar town and its suburbs, Ethiopia," BMC Public Health, vol. 12, no. 1, p. 950, 2012.

[65] S. Costalunga and E. C. Tondo, "Salmonellosis in Rio Grande do Sul, Brazil, 1997 to 1999," Brazilian Journal of Microbiology, vol. 33, pp. 38-43, 2002.

[66] G. Kebede and M. Ashenafi, "Microbiological quality and safety of custard cakes from Addis Ababa, A short communication," Ethiopian Journal of Biological Science, vol. 9, no. 2, pp. 173-181, 2010.

[67] W. Molla, B. Molla, D. Alemayehu, A. Muckle, L. Cole, and E. Wilkie, "Occurrence and antimicrobial resistance of Salmonella serovars in apparently healthy slaughtered sheep and goats of central Ethiopia," Tropical Animal Health and Production, vol. 38, no. 6, pp. 455-462, 2006.

[68] B. Sibhat, B. Molla Zewde, A. Zerihun et al., "Salmonella serovars and antimicrobial resistance profiles in beef cattle, slaughterhouse personnel and slaughterhouse environment in Ethiopia," Zoonoses and Public Health, vol. 58, no. 2, pp. 102-109, 2011.

[69] S. N. Al-Bahry, A. E. Elshafie, S. Al-Busaidy, J. Al-Hinai, and I. Al-Shidi, "Antibiotic resistant Salmonella spp. from human and non-human sources in Oman," Eastern Mediterranean Health Journal, vol. 3, pp. 49-55, 2007. 
[70] M. L. Khaitsa, R. B. Kegode, and D. K. Doetkott, "Occurrence of antimicrobial-resistant Salmonella species in raw and ready to eat Turkey meat products from retail outlets in the midwestern United States," Foodborne Pathogens and Disease, vol. 4, no. 4, pp. 517-525, 2007.

[71] B. A. Gebre, "Qualitative screening of antibiotic residues and identification of antibiotic resistant Salmonella from raw and ready to eat meat in Thailand," International Journal of Advanced Life Sciences, vol. 5, pp. 51-64, 2012.

[72] A. Stevens, Y. Kabore, J. Perriergrosclaude et al., "Prevalence and antibiotic-resistance of Salmonella isolated from beef sampled from the slaughterhouse and from retailers in Dakar (Senegal)," International Journal of Food Microbiology, vol. 110, no. 2, pp. 178-186, 2006.

[73] G. Tadesse, "A meta-analysis of the proportion of animal Salmonella isolates resistant to drugs used against human salmonellosis in Ethiopia," BMC Infectious Disease, vol. 15, no. 1, Article ID 84, 2015.

[74] S. Domingues, K. Harms, W. Florian Fricke, P. J. Johnsen, G. J. da Silva, and K. M. Nielsen, "Natural transformation facilitates transfer of transposons, integrons and gene cassettes between bacterial species," PLoS Pathogens, vol. 8, no. 8, Article ID e1002837, 2012.

[75] T. Eguale, E. Engidawork, and W. A. Gebreyes, "Fecal prevalence, serotype distribution and antimicrobial resistance of Salmonellae in dairy cattle in central Ethiopia," $B M C$ Microbiology, vol. 16, no. 1, Article ID 20, 2016.

[76] M. Maru, S. H. Mariam, T. Airgecho, E. Gadissa, and A. Aseffa, "Prevalence of tuberculosis, drug susceptibility testing, and genotyping of mycobacterial isolates from pulmonary tuberculosis patients in Dessie, Ethiopia," Tuberculosis Research and Treatment, vol. 2015, Article ID 215015, 10 pages, 2015. 